\title{
The Cytotoxic Effect of the Extract of Anchusa strigosa (Him Him) Grown in Jordan Against Different Cancer Cell Lines
}

\author{
Arwa Al-Khatib ${ }^{1^{*}}$ \\ Iqbal Al-Khateeb ${ }^{1}$ \\ Rana Abu-Dahab ${ }^{2}$ \\ Naseer Al-Rawi ${ }^{3}$ \\ ${ }^{1}$ Department of Pharmaceutical Sciences, Faculty of Pharmacy, PDRC, Al-Ahliyya Amman University, Amman, \\ Jordan. \\ ${ }^{2}$ Faculty of Pharmacy, University of Jordan, Amman, Jordan \\ ${ }^{3}$ Department of Biopharmaceutics and Clinical Pharmacy, Faculty of Pharmacy, PDRC, Al-Ahliyya Amman University, \\ Amman, Jordan. \\ *Corresponding author: a.alkhatib@ammanu.edu.jo *,ialkhateeb@ammanu.edu.jo, abudahab@ju.edu.jo, \\ n.rawi@ammanu.edu.jo
}

*ORCID ID: https://orcid.org/0000-0001-9445-3315*, https://orcid.org/0000-0002-3569-0393 , https://orcid.org/00000003-0857-7616, https://orcid.org/0000-0001-9374-4946

Received 12/1/2020, Accepted 1/11/2020, Published Online First 6/12/2020, Published 1/3/2021

This work is licensed under a Creative Commons Attribution 4.0 International License.

\begin{abstract}
:
Anchusa strigosa - prickly alkanet from Boraginaceae grows in roadsides, and fields of a broad range of habitats from mediterranean woodlands, to steppe vegetation, to true desert. It is commonly known as" him him" or "lisan al thawr". Anchusa can withstand hard weather conditions and hence is widely cultivated. The color of its flowers can range from pure white to deep cobalt blue. Various parts of A. strigosa are used in traditional medicine for treating several diseases or symptoms, such as abdominal pain, bronchitis, cough, and diarrhea. The goal of this study was to examine the cytotoxic effect of the crude extract of $A$. strigosa roots and leaves and their fractions against various tumor cell lines: adenocarcinoma MCF-7, human breast ductal carcinoma T-47D; human breast carcinoma MDA-MB-231; and colorectal carcinomas Caco-2. In conclusion the antiproliferative effect was assessed by SRB assay where it showed that the phytochemical constituents in the leaf part of the plant (A. strigosa) do have more potential in depressing the proliferation rate of the cell lines than the root part.
\end{abstract}

Key words: Anchusa strigosa, Caco-2, MCF-7, MDA-MB 231

\section{Introduction:}

Natural products played a major role in chemical biology and drug discovery (1). They were used for a long time to cure cancer, which has become one of the major causes of death in the world.

Prevention of cancer is undeniably the ultimate goal of cancer control or eradication, especially when the major etiological factors are known. However, the number of deaths due to cancer is increasing on an annual basis. Hence, the philosophical treatment is of little consequence, systemic chemotherapy remains the primary method of attacking such a widespread disease, and there is obviously a vital need for discovering new clinically efficacious agents (2).

It is well-known that Anchusa is used in traditional medicine for treating several diseases or symptoms (3), due to its antimicrobial, antioxidant (4) ,anti-ulcer (5), anti-diabetic (6) ,demulcent, diaphoretic activities (6). Recent studies have pointed that the mechanisms behind the chemopreventive action may include one or more of the antioxidant (8) anti-inflammatory, immuneenhancing, and antihormone effect (9).

The discovery of the fact that tumor-derived cell lines proliferate indefinitely promoted the recent understanding of cancers, and represents the basis of pioneering in vitro anticancer drug discovery and testing initiatives. Specifically by the early 1990s, a huge number of human tumor cell lines have been established, and it was just the time for extensive anticancer drug discovery in the newly available 96-well high-throughput screening (HTS) format. However, early indication whether a novel compound can be effective in a living system or not depends on the right choice of cell line and the optimal endpoint measured. A number of methods have been developed to study cell viability and 
proliferation in cell cultures. The most convenient assays have been optimized for the use of 96-well plates. This miniaturization allows many samples to be analyzed rapidly and simultaneously. With the objective of evaluating the cytotoxic activity of the root and leaf parts' extracts of A. strigosa and their fractions against various tumor cell lines, this study examined the percentage of survival rates of different cancer cells following 72 hour exposure to the plant extracts where the leaf extract of $A$. strigosa exhibited somehow better result than the root extracts and fractions in suppressing the growth of cancer cells.

\section{Materials and Methods:}

The roots and leaves of $A$. strigosa plant that is grown in Jordan were collected from Al-Salt city in Albalqa'a, and was authenticated by a chemotaxanomist (Dr. Daood Al-Esawi) University of Jordan.

A.strigosa roots and leaves were extracted by different methods of extraction including the cold maceration, and the soxhlet apparatus, using a wide range of solvents of different polarities (chloroform, methanol, ethanol, petroleum ether, etc)(Figs. 1 and 2). Furthermore, fractions were analyzed by preparative TLC to isolate the pure compounds (10),then the isolated compounds were identified by TLC and chemical reagents (11). Finally, the extracts and their fractions were tested by SRB assay to check their cytotoxic activity against MCF-7, MDA-MB-231, T-47D and Caco2 cell lines.

Antiproliferative effect was assessed by SRB assay where it showed that the phytochemical constituents in the leaf part of the plant (A. strigosa) do have more potential in depressing the proliferation rate of the cell lines than the root part.

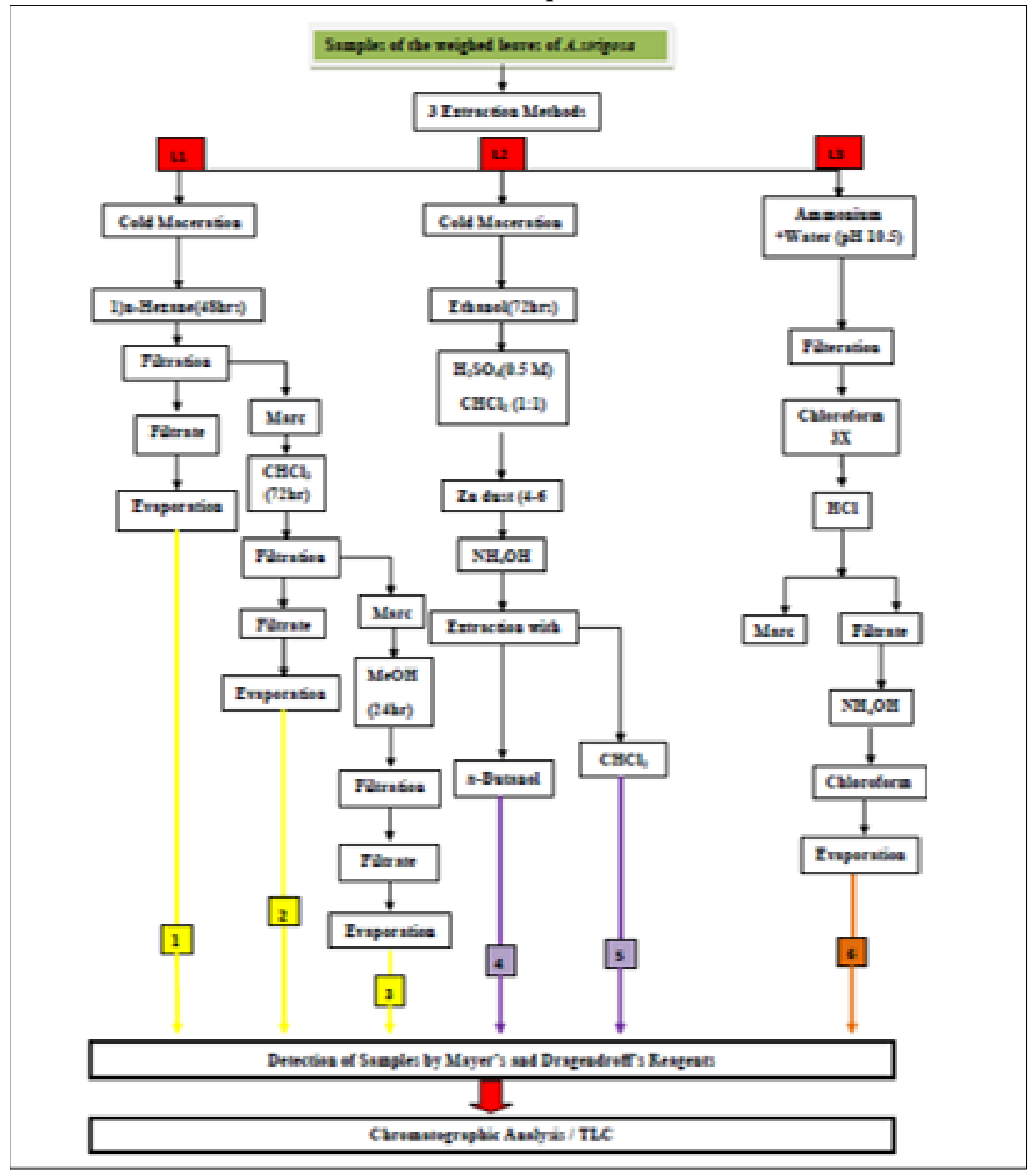

Figure 1. General Scheme of Extraction of the Leaves of Anchusa strigosa $(12,13)$ 


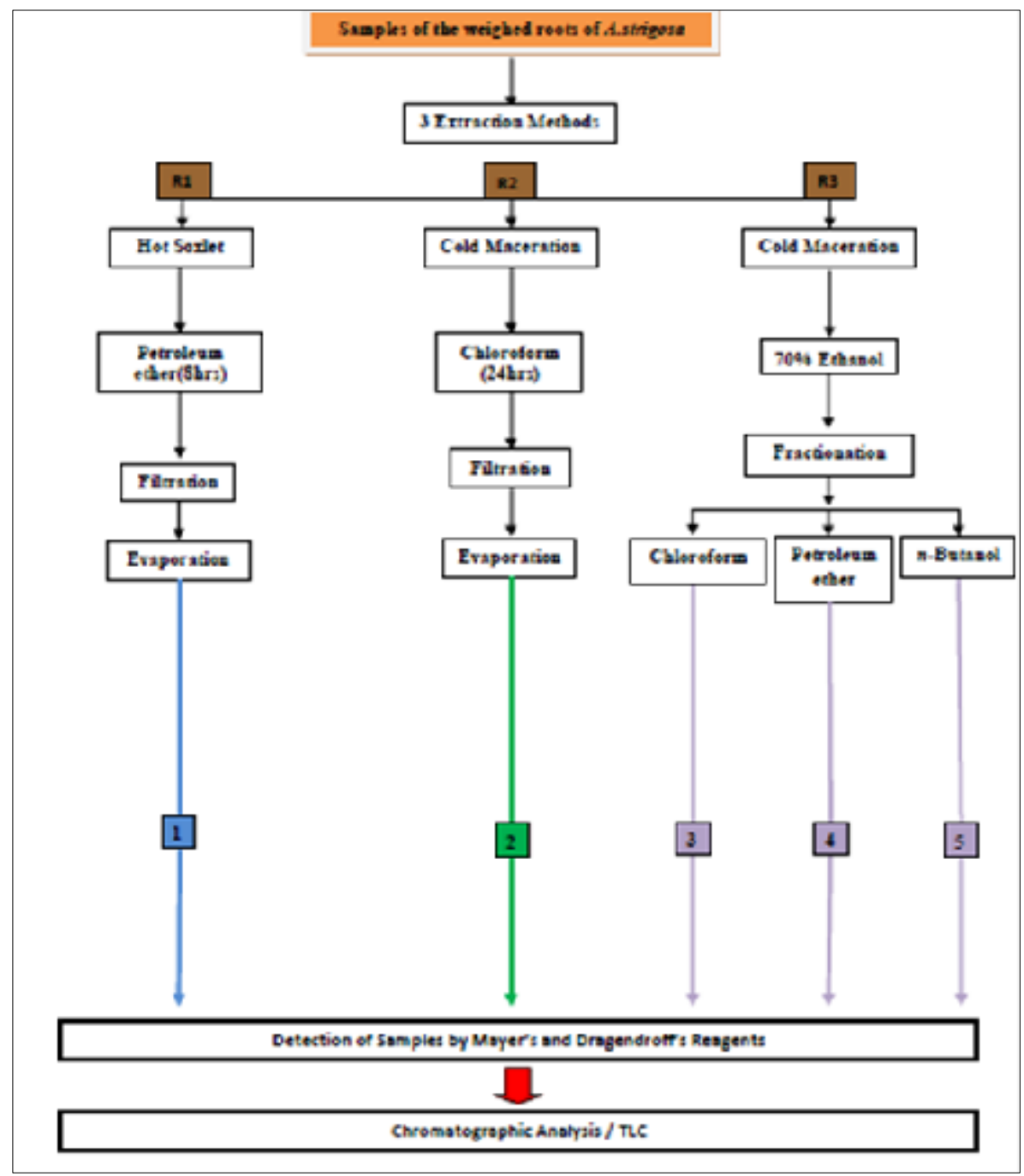

Figure 2. General Scheme of Extraction of the Root of Anchusa strigosa $(13,14)$

Preparation of the Samples for Cytotoxic Analysis

All the samples were dissolved in DMSO (Dimethyl sulfoxide) in a ratio of weight of sample to volume of solvent as follows: each $0.1 \mathrm{~g}$ of sample should be dissolved in $10 \mathrm{ml}$ DMSO (15). The first batch of samples that were used in cytotoxic analysis was coded as Fig. 2 (Root samples $-1,2,3,4,5)(13)$.

\section{Extracts Pretreatment for Cytotoxic Assay}

We dissolve $0.1 \mathrm{~g}$ of plant extract in $10 \mathrm{ml}$ DMSO. Then to $15 \mu$ of this preparation, we added fresh media to complete the volume to $3 \mathrm{ml}$ (16) .

\section{Antiproliferative Assay}

The cells were plated in 96-well plates (Greiner Bio-One, Germany) for all the experiments. $100 \mu \mathrm{l}$ of cell suspension was used in each well. After initial experiments, the cell densities for optimal growth was found to be 5000 cells/well in cases of both MCF-7, and T-47D; so as to ensure exponential growth throughout the experimental period and to ensure a linear relationship between absorbance at $570 \mathrm{~nm}$ and cell number when analyzed by SRB assay. Therefore, $100 \mu$ of the previous cell suspension was seeded in 96-well plate and incubated at $37{ }^{\circ} \mathrm{C}$ to allow cell attachment, for 24 hours before the addition of the extracts. $100 \mu \mathrm{l} /$ well was added to the plates in six replicates.

The final dilution used for treating the cells contained not more than $1 \%$ of the initial solvent DMSO. Reports indicated that at this concentration DMSO was not cytotoxic (17). Hence, $1 \%$ DMSO was used as a control solvent in the present experiments. However, $100 \mu \mathrm{l}$ of medium was added to cell-free wells for background control.

After the application of the extracts, we incubated the plates for 72 hours, based on the finding of the preliminary studies indicating the exponential growth phase of each cell line is to be between 24-72 hours (18). Finally, we analyze the growth using SRB assay (19), we used three replicate plates were used to determine the cytotoxicity of each extract (20). Then cells were 
incubated with a wide range of concentrations serially diluted from $(250 \mu \mathrm{g} / \mathrm{ml})$ to $(3.9 \mu \mathrm{g} / \mathrm{ml})$ for 72 hours, then cell viability was evaluated using $\mathrm{SRB}$, where the cells were fixed by layering icecold $40 \%$ trichloroacetic acid on top of the growth media. Cells were incubated at $4{ }^{\circ} \mathrm{C}$ for one hour, after that, plates were washed with cold water five times. Then, the excess water was drained off and sucked by an electrical pump, plates were left aside at room temperature for another 5 minutes to ensure complete drying. We added SRB stain to each well and left it in contact with the cells for 30 minutes, after that we washed all the cells with $1 \%$ acetic acid, rinsed them four times until only dye adhering to the cells was left. We dried the plates at room temperature and added $100 \mu \mathrm{l}$ of $10 \mathrm{mM}$ Tris base ( $\mathrm{pH} 10.5)$ to each well to solubilize the dye. The plates were shaken gently for 15 minutes on a plate
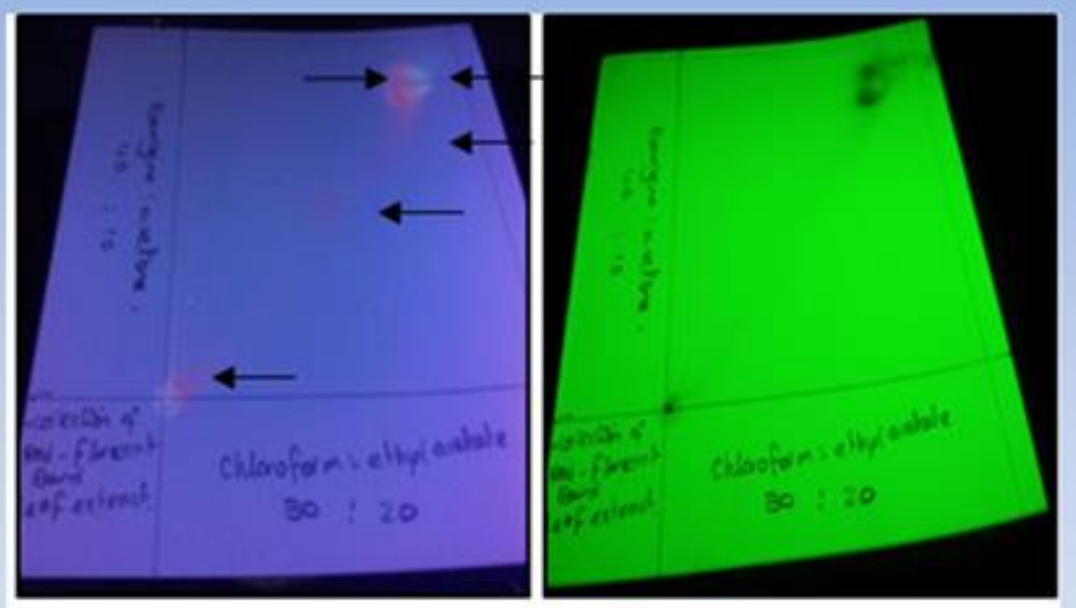

Figure 3. Two-dimensional TLC of the red band out of the root extract under wavelength $254 \mathrm{~nm}$ and $365 \mathrm{~nm}$.

\section{Results of cytotoxic assays:}

In the present study we examined the cytotoxic effect of the crude extract of A. strigosa roots and leaves and their fractions against various tumor cell lines: adenocarcinoma MCF-7, human breast ductal carcinoma T-47D; human breast carcinoma MDA-MB-231, and colorectal carcinomas Caco-2.

\section{MCF-7 cells:}

The control was DMSO with the same concentration $(25 \mu \mathrm{g} / \mathrm{ml})$, in addition to cisplatin which was used as a standard reference anticancer agent (positive control) that showed cytotoxic effect on the MCF-7 cell lines. The data presented in the Table 1 showed the mean of proliferation rate of all the samples including the total extracts and their fractions. shaker then the absorbance of each well was read by ELISA plate reader at $570 \mathrm{~nm}$. Cell survival rate or relative cell viability was expressed in terms of the mean percentage of viable cells in comparison with DMSO-treated cells (control).

Cisplatin (Ebewe PharmaGes., Austria) was used as standard anticancer agent representing the positive controls.

\section{Results:}

Results of the reaction between the total extracts and some of their fractions with Dragendroff's and Mayer's reagent showed that most of the samples gave positive results with minor variations in the intensity of the results, and identified by TLC as Fig.3 . 


\section{MDA-MB-231:}

As it can be noticed in the Table 2, the leaf extract of A.strigosa exhibited somehow a better result than the other extracts and fractions, but yet it cannot be considered to have a cytotoxic activity against the MDA-MB-231 cell lines.

Table 2. Percentage of cell survival rate of MDAMB-231cells following 72hour exposure to 25 $\mu \mathrm{g} / \mathrm{ml}$ of plant extracts.

\begin{tabular}{lll}
\hline Samples & $\begin{array}{l}\text { Mean of \% } \\
\text { proliferation } \\
\text { rate }\end{array}$ & \\
& 60.16 & \pm 0.37 \\
\hline Leaf extract -n-hexane L1 & 70.80 & \pm 0.18 \\
Leaf extract-chloroform L1 & 78.94 & \pm 1.82 \\
Leaf extract-70\% ethanol L2 & 82.36 & \pm 0.76 \\
Root extract-chloroform R2 & 87.14 & \pm 0.40 \\
Root extract-70\% ethanol R3 & & \\
\hline *SD: standard deviation & & \\
Results are expressed as (mean $\%$ & \pm standard deviation) of four \\
replicates done &
\end{tabular}

\section{T-47D Cells:}

However, in the case of T47D cell lines the result of the leaf extract out of chloroform is considered the best among all samples as shown in the Table 3.

Table 3. Percentage of cell survival rate of T-47D cells following $72 \mathrm{hour}$ exposure to $25 \mu \mathrm{g} / \mathrm{ml}$ of plant extracts.

\begin{tabular}{lll}
\hline Sample & $\begin{array}{l}\text { Mean of } \% \\
\text { proliferation rate }\end{array}$ & $*$ SD \\
\hline Leaf extract -n-hexane L1 & 79.99 & \pm 1.68 \\
Leaf extract-chloroform L1 & 62.68 & \pm 1.57 \\
Leaf extract-70\% ethanol L2 & 78.58 & \pm 4.40 \\
Root extract-chloroform R2 & 68.77 & \pm 1.37 \\
Root extract-70\% ethanol R3 & 80.31 & \pm 1.84 \\
\hline
\end{tabular}

*SD: standard deviation

Results are expressed as (mean $\% \pm$ standard deviation) of four replicates done

\section{Caco-2 Cells:}

However, regarding the Caco- 2 cell lines, both leaf and root extracts are considered to have no noticeable cytotoxic action since the percentage of survival rate was not less than $50 \%$ (Table 4).

Table 4. Percentage of cell survival rate of Caco2 cells following $72 \mathrm{hour}$ exposure to $25 \mu \mathrm{g} / \mathrm{ml}$ of plant extracts.

\begin{tabular}{llr}
\hline Sample & $\begin{array}{l}\text { Mean of } \% \\
\text { proliferation rate }\end{array}$ & $* \mathrm{SD}$ \\
\hline Leaf extract -n-hexane L1 & 80.69 & \pm 1.08 \\
Leaf extract-chloroform L1 & 71.68 & \pm 1.87 \\
Leaf extract-70\% ethanol L2 & 88.61 & \pm 1.39 \\
Root extract-chloroform R2 & 74.92 & \pm 3.17 \\
Root extract-70\% ethanol R3 & 75.64 & \pm 0.42 \\
\hline *SD: standard deviation & & \\
Results are expressed as (mean \% & standard deviation) of four \\
replicates done & &
\end{tabular}

Regarding the antiproliferative effect against the Caco- 2 cell lines, the leaf extract out of chloroform exerted the best result among all tested samples, but again it was of a lesser effect than in case of the previous result against the T-47D cell lines.

\section{Discussion:}

In reference to all the prior results of the SRB assay on different cell lines, ranging from the MCF-7, MDA-MB-231, T-47D, to Caco-2, it can be concluded that $A$. strigosa total extracts of both the leaves and root, in addition to their fractions have noticeable variations among their percentage proliferation rates depending on the specific type of extract. This suggests that various types of cell lines differ in their sensitivity to the same plant extract. It was noticed from the previous results that the phytochemical constituents in the leaf part of the plant (A. strigosa) do have more potential in depressing the proliferation rate of the cell lines than the root part. This might be due to the presence of tannins only in the leaf part, or the fact of having the highest proportion of pyrrolizidine alkaloids in this part. Moreover, the weak cytotoxic effect (\% proliferation rate) Tables $(1,2,3,4)$ may be due to an antagonistic effect of the other compounds present within the total extract form on the phenolic acids that are known to exhibit an antioxidant activity (8). Going back to the finding that shikonin which is present in the roots of $A$. strigosa does have antitumor effect by inhibiting the proliferation of cancer cells; in addition to its wound healing activity (5). Moreover, it has to be noted that it takes from 5 to 7 years for the concentration of shikonin to reach $2 \%$ of the total percentage yield in the roots, thus getting not enough amount of this active constituent which in turn may comply for getting such a result. In reference to Fig. 3 of twodimensional TLC which showed that the root sample was present in an impure form (more than one component).On the other hand alkannin, the enantiomer of shikonin is known to have antiinflammatory effects without exerting any antitumor actions. Accordingly, there are several factors that affect the formation of shikonnin which were mentioned earlier in this study, which in turn might agree with getting no cytotoxic activity due to inhibition of shikonnin formation such as presence of ammonia in soil for instance, light factor, or any other aspects.

Regarding the pyrrolizidine alkaloid content in A. strigosa, it has to be cleared that this active component consists of three non-toxic constituents in addition to four other toxic alkaloids (12), so focusing on the fact that the variation in the 
percentage of both types can acquiesce for such a result too. Nevertheless, previous phytochemical assays reported that the IC50 values of pyrrolizidine alkaloids reached almost $100 \mu \mathrm{g} / \mathrm{ml}$ which is in turn considered to be of a high range comparatively to the concentration present in our total extracts' forms (21). Last but not least, the other factors that may have resulted in getting weak cytotoxic activity can be the presence or absence of certain active constituents depending on the environmental factors, soil type, and fertility. In addition to the fact of the presence of such active component as a specific compound in a pure isolated form so as to exert an antitumor action, which in turn can be missed if this similar component is present as a part of a total extract mixture. One more point to be taken into consideration is that early indication whether a novel compound can be effective in a living system or not depends on the right choice of cell line, for instance, since A. strigosa has been reported to have an antiulcer activity, and was used for healing wounds, thus it is preferably considered to have a cytotoxic effect against melanoma cell lines, which were unfortunately very hard to be provided during this study.

\section{Conclusion:}

In conclusion, this current study reported the presence of alkaloids in both the leaf and root parts of A. strigosa plant.

However, the leaf extracts have shown more potential in suppressing the proliferation rate than the root extracts of the plant in study. Therefore, reasons behind such a finding can be examined in other upcoming studies.

Further studies are needed to determine the antiproliferative activity of A. strigosa on other types of cell lines that were not detected in this work such as melanoma and leukemia cell lines. Investigations of the effect of the environmental factors on the different active components composition in A. strigosa can also be performed.

\section{Acknowledgment:}

My gratitude goes to Al-Ahliyya Amman University, Amman, Jordan for giving me the opportunity to perform and present this study.

\section{Authors' declaration:}

- Conflicts of Interest: None.

- We hereby confirm that all the Figures and Tables in the manuscript are mine ours. Besides, the Figures and images, which are not mine ours, have been given the permission for republication attached with the manuscript.
- The author has signed an animal welfare statement.

- Ethical Clearance: The project was approved by the local ethical committee in University of Jordan.

\section{References:}

1. Torki A, Khalaji-Pirbalouty V, Lorigooini Z, Rafieian-Kopaei M, Sadeghimanesh A, Rabiei Z. Anchusa italica extract: phytochemical and neuroprotective evaluation on global cerebral ischemia and reperfusion. Brazilian J. Pharm. Sci. 2018;54 (1).

2. Suffness M. Assays related to cancer drug discovery. Methods in plant biochemistry: assays for bioactivity, 1990, 6: 71-133(2).

3. Oran S, Al-Esawi D. Medicinal plants in the high mountains of northern Jordan. Int. J. Biodivers. Conserv. 2014, 6.6: 436-443(3).

4. Alali FQ, Tawaha K, El-Elimat T, Syouf M, El-Fayad $\mathrm{M}$, Abulaila K, et al. Antioxidant activity and total phenolic content of aqueous and methanolic extracts of Jordanian plants: an ICBG project. Nat Prod Res . 2007 Oct 1;21(12):1121-31.

5. Asnaashari S, Dastmalchi S, Javadzadeh Y. Gastroprotective effects of herbal medicines (roots). Int J Food Prop. 2018, 21.1: 902-920(5).

6. Muhammed A, Ari N. Antidiabetic activity of the aqueous extract of Anchusa strigosa Lab in streptozotocin diabetic rats. Int J Pharm. 2012; 2.3: 445-49(6).

7. Al-Snafi E. The pharmacology of Anchusa italica and Anchusa strigosa-A review. Int $\mathbf{J}$ Pharm Pharm Sci. 2014; 6.4: 7-10(7)

8. Merlani M, Barbakadze V, Gogilashvili L, Amiranashvili L. Antioxidant activity of caffeic acidderived polymer from Anchusa italica. Bull. Georg. Natl. Acad. Sci, 2017; 11.2: 123-127(8).

9. Alallan L, Agha MI, Omerein AN, Al Balkhi MH. Anti-arthritic effects of Anchusa strigosa extracts on complete Freund's adjuvant-induced arthritis in rats. Journal of Pharmacognosy and Phytochemistry, 2018, 7.6: 679-685(9).

10. Chen KK, Xie ZJ, Dai W, Wang Q.A new oleanolictype triterpene glycoside from Anchusa italica. Nat Prod Res. 2017; 31.8: 959-965(10).

11. Boskovic I, Đukić DA, Maskovic P, Mandić L, Perovic S. Phytochemical composition and antimicrobial, antioxidant and cytotoxic activities of Anchusa officinalis L. extracts. Biologia. 2018 Nov 1;73(11):1035-41

12. Dominguez DM, Reina M, Santos-Guerra A, Santana O, Agulló T, López-Balboa C, et al. Pyrrolizidine alkaloids from Canarian endemic plants and their biological effects. Biochemical Systematics and Ecology. 2008; 36.3: 153-166(12).

13. Abbas M, Disi A, Al-Khalil S. Isolation and Identification of anti-ulcer components from Anchusa strigosa root. Jordan J. Pharm. Sci. 2009; 2.2: 131139(13). 
14. Al-Juobory TS, Al-Ameri A K, Al-Salihi F G. Antimicrobial activity of total lipids extracted from Anchusa strigosa Lab. Journal of Surra Man Raa. 2007; 3.6: 11-20(14).

15. Phelan K, May Kristin M. Basic techniques in mammalian cell tissue culture. Curr Protoc Cell Biol. 2015; 66.1: 1.1. 1-1.1. 22(15).

16. Khurm M, Chaudhry BA, Uzair M, Janbaz KH. Antimicrobial, Cytotoxic, Phytotoxic and Antioxidant Potential of Heliotropium strigosum Willd. Medicines. 2016 Sep;3(3):20.

17. Itharat A, Houghton PJ, Eno-Amooquaye E, Burke PJ, Sampson JH, Raman A. In vitro cytotoxic activity of Thai medicinal plants used traditionally to treat cancer. J Ethnopharmacol. 2004; 90.1: 33-38(17).

18. Abu-Dahab R, Hakooz N. A trend of low serum vitamin B12 in Jordanian adults from two ethnic groups in Amman. Jordanian Med. J. 2006; 40: 8087(18).

19. Orellana E A, Kasinski A L. Sulforhodamine B (SRB) assay in cell culture to investigate cell proliferation. Bio-protocol. 2016; 6.21(19).

20. Ezhilarasi AA, Vijaya JJ, Kaviyarasu K, Maaza M, Ayeshamariam A, Kennedy LJ. Green synthesis of $\mathrm{NiO}$ nanoparticles using Moringa oleifera extract and their biomedical applications: Cytotoxicity effect of nanoparticles against HT-29 cancer cells. J Photochem Photobiol B. 2016 Nov 1;164:352-60.

21. El-Shazly A, Wink M. Diversity of pyrrolizidine alkaloids in the Boraginaceae structures, distribution, and biological properties. Diversity. 2014; 6.2: 188282(21).

\section{التأثير السمّي لمستخلص نبات لسان الثور(حمح) النامي في الأردن ضد خطوط الخلايا السرطاتية المختلفة}

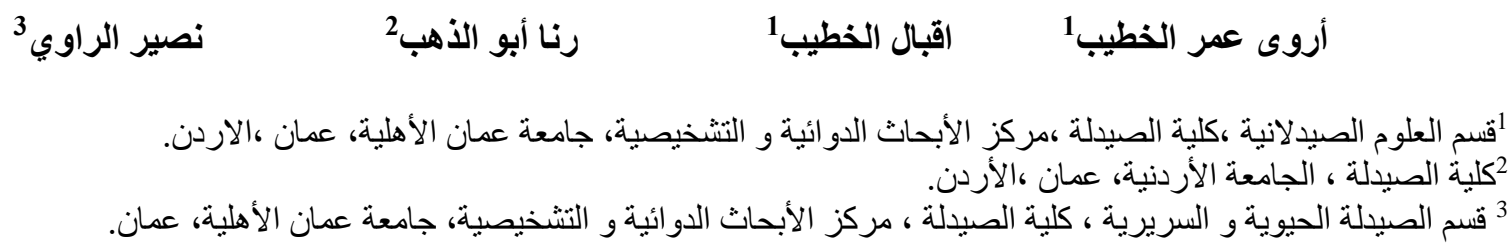

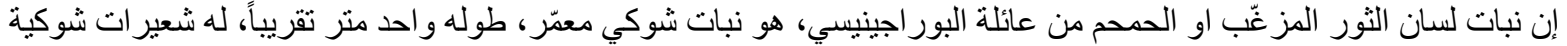

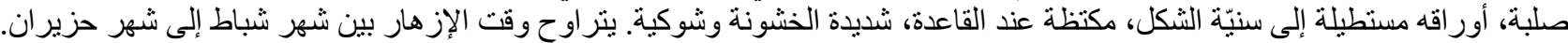

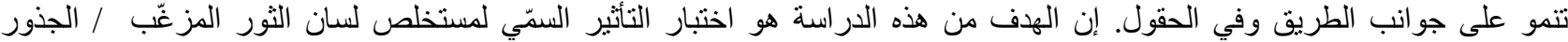

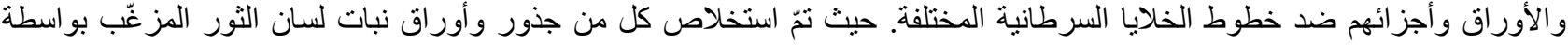

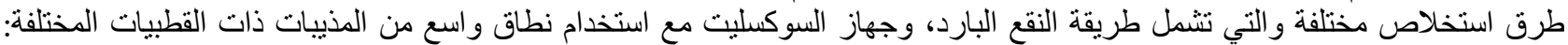

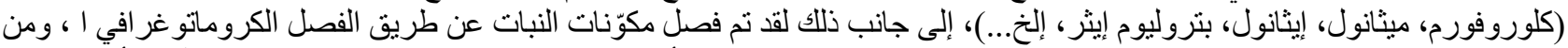

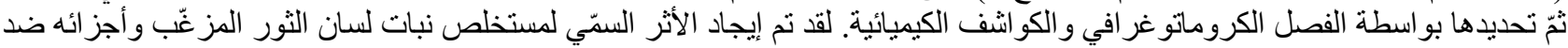

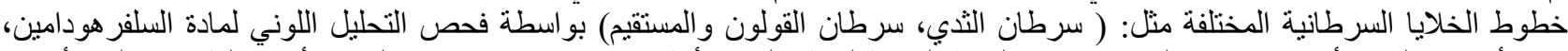

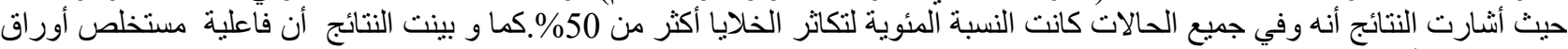

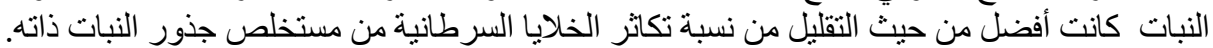

الكلمات المفتاحية: نبات لسان الثور، خطوط خلايا سرطان الثدي، الخط الخلوي السرطاني المتتقل، الخط الخلوي السرطاني للقولون و 